\title{
Rapid Development of First Person Serious Games using the APEX Platform: The Asthma Game
}

\author{
Tiago Gomes \\ Departamento de Informática, \\ Universidade do Minho \& \\ HASLab/INESC TEC \\ Braga, Portugal \\ pg19814@alunos.uminho.pt
}

\author{
Tiago Abade \\ Departamento de Informática, \\ Universidade do Minho \& \\ HASLab/INESC TEC \\ Braga, Portugal \\ pg20691@alunos.uminho.pt
}

\author{
José C. Campos \\ Departamento de Informática, \\ Universidade do Minho \& \\ HASLab/INESC TEC \\ Braga, Portugal \\ jose.campos@di.uminho.pt
}

\author{
Michael Harrison \\ Queen Mary University \\ London \& Newcastle \\ University \\ United Kingdom
}

michael.harrison@newcastle.ac.uk

\begin{abstract}
Serious games combine a ludic component with instructive and formative goals. They aim to educate and train through play. This paper explores the use of a development framework for dynamic virtual environments to develop serious games. The framework (APEX) was originally developed to prototype ubiquitous computing environments. Here it is used to develop a first person serious game: the Asthma Game. This game aims to teach children with asthma how to act to prevent attacks by drawing attention to asthma triggers in the home, and by providing information about how to avoid them. Besides the description of the game, results about the viability and utility of the approach are also discussed.
\end{abstract}

\section{Categories and Subject Descriptors}

H.5.1 [Information Interfaces and Presentation (e.g., HCI)]: Multimedia Information Systems-Artificial, augmented, and virtual realities; K.3.1 [Computers and Education]: Computer Uses in Education; K.8.0 [Personal Computing]: General-Games

\section{General Terms}

Human Factors, Design

\section{Keywords}

Serious Games, Asthma, Virtual Environments

Permission to make digital or hard copies of all or part of this work for personal or classroom use is granted without fee provided that copies are not made or distributed for profit or commercial advantage and that copies bear this notice and the full citation on the first page. Copyrights for components of this work owned by others than the author(s) must be honored. Abstracting with credit is permitted. To copy otherwise, or republish, to post on servers or to redistribute to lists, requires prior specific permission and/or a fee. Request permissions from Permissions@acm.org.

SAC 2014 March 24-28, 2014, Gyeongju, Korea.

Copyright is held by the owner/author(s). Publication rights licensed to ACM.

ACM 978-1-4503-2469-4/14/03 . .\$15.00.

http://dx.doi.org/10.1145/2554850.2554969.

\section{INTRODUCTION}

Serious games combine playing with learning. Games can be used to educate and train as well as to play. Mike Zyda [12] defines a Serious Game as a mental competition, played with a computer in accordance with specific rules, that uses entertainment to promote training, education, health, public policy and strategic communications objectives. The use of games for such purposes has a long history that pre-dates computer gaming [1].

Health education is one area where the use of serious games is being explored [3, 11]. Games are particularly relevant for young people who are familiar with the use of virtual environments $[8,4]$ to create a first person experience. Of particular relevance here are first person games where users control an avatar placed within a three dimensional (3D) virtual world. Through the avatar, it is possible to explore and interact with the world.

Considerable work is being carried out to explore how best to design games such as these (see, for example, $[3,11,8$, 4]). This article takes an engineering perspective to explore their development. The APEX platform [10] provides an infrastructure for the prototyping and creation of virtual environments, as well as the definition of behaviors in these environments. Such environments will underpin the games to be developed.

The game, that was developed, addresses the problems faced by children with asthma. Asthma is a chronic disease and specific procedures can be used to prevent the emergence of crises. The goal of the game is to teach these procedures to relevant children at elementary school level. A user study was carried out to validate the use of the APEX platform to support the development of serious games and to explore the effectiveness of the game itself.

The paper is organized as follows. Section 2 provides a brief presentation of the APEX platform. Section 3 describes the developed game. Section 4 describes the study conducted to validate the game. The conclusions of this validation are also discussed. Section 5 presents a redesign of the game, carried out to address the concerns identified in the study. Finally, Section 6 describes conclusions to be drawn and provides pointers to future work. 


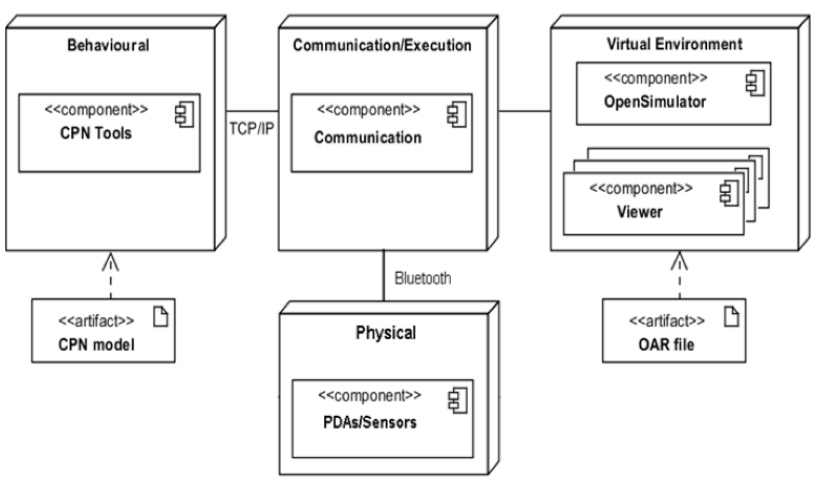

Figure 1: Architecture of the APEX framework

\section{THE APEX PLATFORM}

The APEX platform (Rapid Prototyping for user EXperience) was originally conceived and developed for the rapid prototyping of ubiquitous computing environments. It is intended to support the simulation and analysis of ubiquitous environments early in the design and development process.

APEX combines components that support prototyping at different levels. The four main components are (see the logical architecture of the platform in Figure 1):

1. Behavioral component - responsible for managing the behavior of the prototype. This component is based on CPN Tools ${ }^{1}$. It uses Coloured Petri Nets (CPN) [6] to describe the behavior of the virtual environment. The model focuses on how the environment responds to user actions, and to changes in the environment (i.e., context changes). This model is used to guide the behavior of the environment. Systematic analysis of the models using CPN tools can detect potential problems in the behavior of the system. This will not be further discussed in this article, see [9] for an example of this type of analysis.

2. Virtual environment/simulation component - responsible for managing the physical appearance of the prototype. This component is based on OpenSimulator ${ }^{2}$, a multi-platform and multi-user 3D application server. OpenSimulator allows both the construction of virtual environments, and access to the environments through appropriate viewers. An example viewer is the Cool VL viewer ${ }^{3}$.

3. Physical component - responsible for managing the connection of external devices to the platform. This component currently supports Bluetooth connections, thereby allowing devices such as smartphones to be integrated into the prototypes.

4. Communication/execution component - responsible for managing the execution of the simulation. This component manages the information exchange carried out among all the other components of the platform, ensuring that they all evolve coherently.

\footnotetext{
${ }^{1}$ http://cpntools.org (last visited 19/09/2013)

${ }^{2}$ http://opensimulator.org/ (last visited 19/09/2013)

${ }^{3}$ http://sldev.free.fr (last visited 19/09/2013)
}

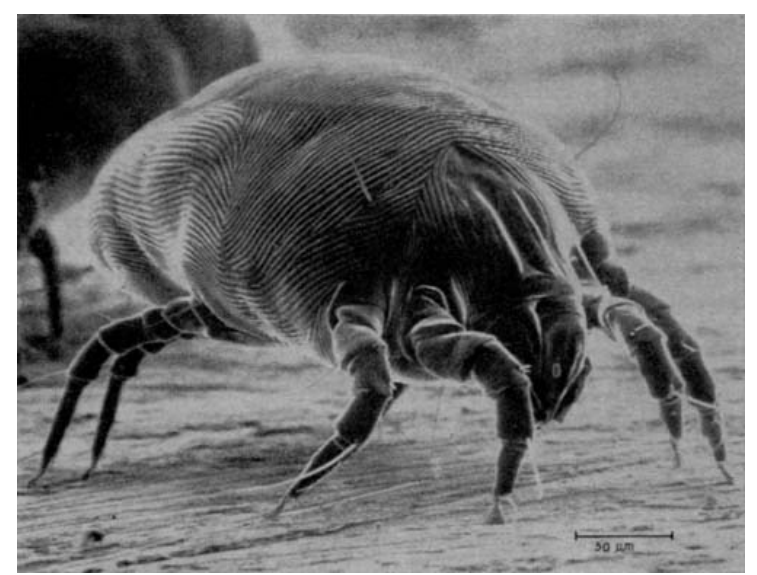

Figure 2: Dust Mites ${ }^{4}$

These components support the prototyping of ubicomp environments using multiple layers. Each layer supports a specific type of evaluation: analysis of model behavior (through the behavioral component); observation of the environment and the behavior of users in the virtual world (through the virtual environment/simulation component), analysis of real objects associated with the virtual world, and the reaction of users in relation to them (through the physical component).

The components can be combined to create the prototype which is best suited to each particular analysis task. For example, when a sensor is to be used in a prototype: its behavior can be modeled in the behavioral component and it can be programmed directly in the virtual environment/simulation component. In addition an actual physical sensor can be included in the prototype through the physical component.

\section{THE ASTHMA GAME}

To illustrate the APEX approach, a game is used that is designed to improve the awareness of children, particularly those suffering from asthma. The aim is to teach children what might trigger an asthma crisis as well as how to respond to these triggers. In this way it is hoped that asthma sufferers may improve their quality of life.

\subsection{Asthma}

Asthma [2] is a chronic inflammatory disease of the respiratory tract. The most common symptoms include wheezing, coughing, chest tightness and shortness of breath. Asthma is a hereditary disease. In most detected cases, there is already a family history of respiratory illnesses.

Asthma attacks can happen for a number of reasons. The most common are the intake of certain drugs through food or medication, and the inhalation of allergenic substances, such as pollen, smoke, animal detritus or dust. Most substances that cause asthma attacks are directly related to the existence of mites (see Figure 2) that are usually found in homes. Upholstery, curtains or clothes can host large communities of mites and cause unwanted reactions in individuals with respiratory illness. There are several procedures to

${ }^{4}$ Image available at (last visited 05/12/2013):

http://en.wikipedia.org/wiki/File:House_Dust_Mite.jpg 


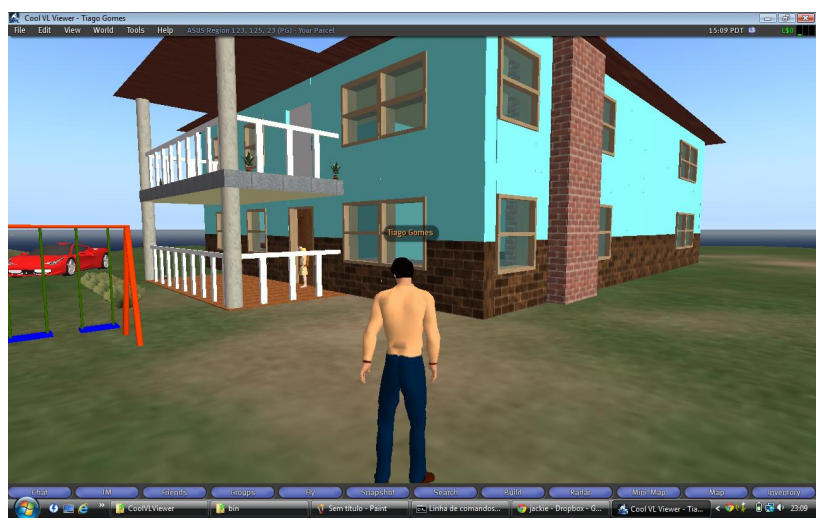

Figure 3: House of the asthma game

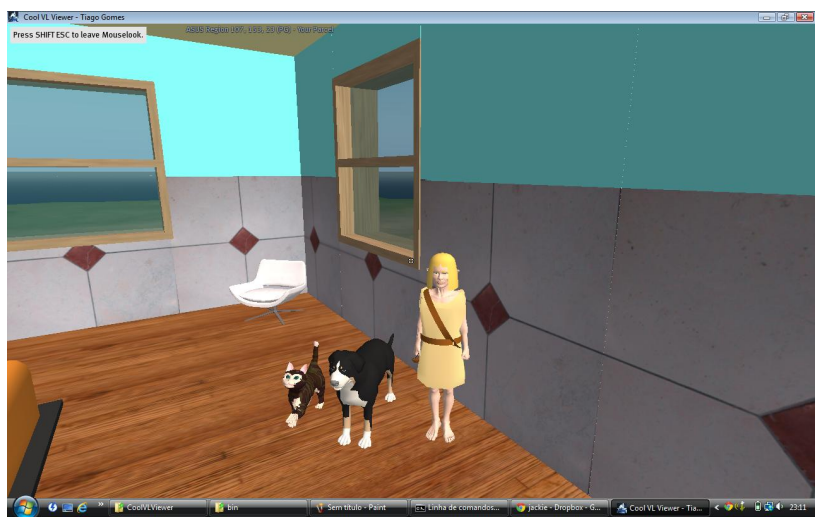

Figure 4: Pets in the bedroom

avoid asthma attacks but these procedures are not always known by asthma sufferers.

Parents and, especially, children need support to identify the causes of asthma attacks and how to avoid them. Governmental and non-governmental institutions have developed checklists (cf. [5]) to instruct people about how they should proceed when faced with the problem of asthma, but these lists are not the most appropriate way to encourage children to learn how to fight it.

\subsection{The game}

The game aims to teach players what basic steps should be taken at home to prevent asthma attacks. The immersive environment allows players to experience everyday situations within the home. It helps situate the decisions that are appropriate when asthma triggers are present.

Game development went through several iterations were different ideas were experimented with. The virtual environment developed (see Figure 3) is inspired by the Aware Home at the Georgia Institute of Technology [7]. The house was furnished as a typical dwelling, using $3 \mathrm{D}$ models from online libraries (e.g., the Trimble 3D Warehouse ${ }^{5}$ ). Furnishings include those that provide a significant source of the causes of asthma attacks. The goal of the game is to enable players to associate asthma causing agents in the virtual en-

${ }^{5}$ http://sketchup.google.com/3dwarehouse/ (last visited $11 / 07 / 2013)$.

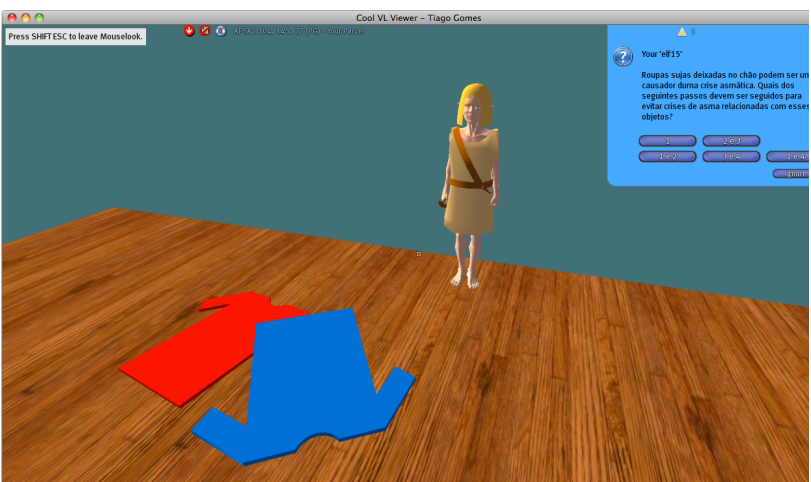

Figure 5: Question about dirty clothes

vironment with real situations that happen in their homes.

The logic of the game was implemented through a combination of LSL (Linden Scripting Language) scripts in the environment component and CPN models in the behavioral component. The flexibility provided by the APEX platform means that different versions of the game could be generated easily. Alternative environments were explored by changing the number and type of asthma triggers present as well as the game logic associated with them. Existing models (from prototypes developed with the framework) were initially used to speed up development.

In the version discussed herein, a total of 9 potential sources for asthma attacks were placed in the house:

- domestic animals (see Figure 4)

- laundry abandoned on the floor (see Figure 5)

- fireplaces (representing smoke)

- soft animal toys

- moldy walls (representing dampness)

- curtains

- blankets

- cleansing products

- carpets

A character represented by an avatar was associated with each trigger (see Figures 4 and 5). It provides the information that is to be learned by players. The characters provide information about the asthma trigger that is near to them. They ask the participants questions about how to avoid their effects. For example, the information and questions relating to cleansing products and laundry are:

- "Cleansing products with intense odors, such as those often used in the cleaning of toilets, can cause asthma attacks. Which of the following steps should be followed to prevent asthma attacks related to these products?"

- "Dirty clothes left on the floor can be a cause of an asthma attack. Which of the following steps should be followed to prevent asthma attacks related to these objects?" 
For each question, players are presented with four possible courses of action. Of these, only two at most are correct. The player must then identify the correct actions from a set of alternatives. The selection is made by pressing the button that corresponds to the desired alternative (see Figure 5).

Illustrations of the information, questions and possible answers given by the character situated next to the pets are as follows.

\section{Domestic Animals}

Pets, such as dogs and cats, can trigger asthma attacks. Which of the following actions should be taken to avoid asthma episodes related to animals?

1. Keep those animals inside the home.

2. If possible, keep the animals out of the home.

3. Let the animals wonder freely in the home.

4. If keeping the animals outside is not possible, at least keep them away from where asthma sufferer sleeps.

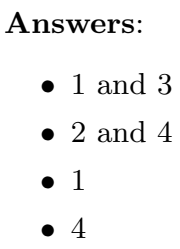

For each correct answer, the player gets a word. At the end of the game the collected words can be used to form a sentence about asthma. This incentive helps players to attempt to answer all questions.

Each player controls an avatar in the virtual world, and is allowed to attempt answering question until the right answer is found. Once all answers have been answered, the player is notified that the game has ended and told how many answers they provided were wrong.

\section{EVALUATION}

A user study was carried out to evaluate the game. The study was set up to address questions related to the usability of the environment, the players' perception of its ability to act as a learning tool, and their satisfaction with it.

\subsection{The user study}

The target audience for the study were children aged 9 to 10 , attending the fourth year of the first level of studies in Portugal. All the targeted children targeted owned a laptop, capable of running the necessary software to interact with the virtual environment. They used their own computers for the study.

As well as logging user actions in the environment, a questionnaire was used to obtain information about the users (age, gender, previous experience with similar games, and previous knowledge of respiratory diseases) and their assessment of the utility and ease of use of the game. The questionnaire also elicited information about their perception of learning. The questionnaire is presented in Annex A. It consists of five sections: Subject characterization; Utility; Ease of use; Learning; and Satisfaction. Because of the age range

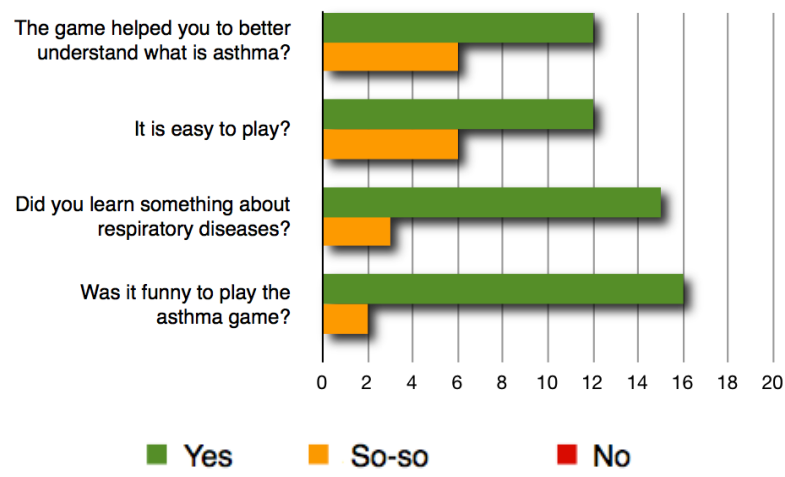

Figure 6: Main results

of the target audience, a simplified 3 point Likert scale was used.

Prior to the study all machines were prepared to support the environment. A viewer (Cool VL Viewer) was preinstalled and configured in a total of 18 machines. As a result the virtual environment running in a server at our laboratories could be accessed.

At the start of the study, participants were provided with information and instruction about how to use the platform. Time was allocated to initial use of the viewer to access the virtual environment. After this initial period all subjects had 30 minutes to play the Asthma game and to answer all the questions. During the experiment three evaluators were present who, besides solving a few technical problems with the machines, mostly observed the users during game play. After the game period, each player answered the questionnaire mentioned above.

\subsection{Results}

The study involved 18 children as participants (11 males and 7 females). None of the children had previous experience with 3D application servers, but 12 stated that they had played computer games before.

Overall, the childrens' reactions to the game were quite positive. According to the data collected through the 18 questionnaires, 16 found the game fun to play, 12 found it easy to play, and 15 felt they had learnt something about respiratory diseases. None answered any questions negatively (see Figure 6)

In the utility section of the questionnaire, twelve children stated that they were able to better understand asthma after playing the game. The same number of children felt that, after playing the game, they were better prepared to help people with respiratory problems. 14 stated that they felt prepared to act in their homes to avoid such problems. They all stated that they considered applying what they had learnt in their homes. The results of this section of the questionnaire can be found in Figure 7 .

In terms of learning, only 2 of the children that played the game found the questions hard. This indicates that the game was seen to be accessible to young players.

In terms of satisfaction, there were also positive results. Fourteen players said they would recommend the game to friends, and none of the others replied negatively to the question (they gave neutral replies). It should be noted that, 


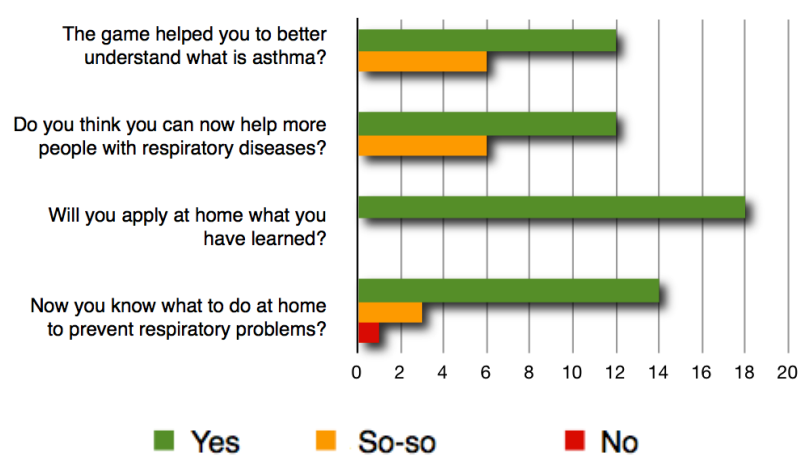

Figure 7: Results from the utility section

since they had the player installed in their laptops and the environment server continued to run after the experiment, some of the players kept playing the game after the user study was over. Both immediately after the study (at school, during their lunch break), and from home.

Despite these quite positive results, none of the players was able to finish the game in the allotted 30 minutes slot. From the observations during game play, it was concluded that certain features of the virtual environment, as well as access to some of the configuration options of the virtual environments' server, contributed to some degree of distraction. In fact, a considerable number of children were more interested in exploring the environment, and interacting with the other players in the environment (chatting, pushing other avatars), than in trying to finish the game by answering the questions.

The main factors that were found to distract children from the purpose of the game were the following:

1. As is usual in the type of environment used for the game, the game was set on an island. One of the main distracting factors was the possibility of going into the sea that surrounded the island to explore the sea bottom.

2. The fact that avatars could fly was another influential distraction during game play.

3. Another aspect that reduced the focus on the game's goal was the ability to create new objects in the virtual world, as well as that of changing already existing ones.

4. Finally, the chat feature present in OpenSimulator provided some distraction.

\section{GAME REDESIGN}

The distractions described in the previous section were detrimental to the ability of the players to reach the end of the game. They affected the game's ability to promote learning about prevention of the symptoms caused by asthma. To better focus users a redesign of the game's environment was carried out.

A major distracting factor was the fact that users could enter and explore the water surrounding the environment. In the second version of the environment a transparent barrier was created between land and water. This served to restrict the playing area to the ground zone. However, users would still have the possibility of entering the water area by activating the flight mode and flying over these barriers. Since the flight functionality was also a major distracting factor this feature was disabled.

The ability to create, change or remove objects in the virtual world was also a distraction. Indeed, in the initial study, a significant number of players lost a good percentage of their playing time using these features. This not only distracted them from the goal of the game, but also the other players who were all sharing the same environment. To avoid these distractions, the environment construction and editing features were blocked. The chat instant messaging, that also contributed to a lack of focus, could not be disabled as it is used during the game to start counting correct and incorrect responses for each player. Since the effect of the chat feature was less strong than other distractions, and allowing some degree of interaction between players was seen to be useful, the feature was kept in the game.

Finally, data logging was improved to enable tracking usage across multiple sessions of the game. This type of information may prove useful for future analysis.

A new user study for the revised version is currently being prepared.

\section{CONCLUSIONS}

Serious Games aim to combine learning with entertainment. Health education is one area where this approach has already proved useful particularly for young people. APEX provides a framework that supports the rapid development of ubiquitous computing environment prototypes. These prototypes simulate the behavior of the intended environments in virtual worlds. This paper explored the use of this approach to develop a serious game.

To demonstrate the feasibility of the approach a game was developed that addresses the problems faced by children with asthma. The intention of the game is to impart knowledge about how to act when faced with factors that might cause asthma attacks. By playing the game it is aimed that children will learn how to avoid attacks. To validate the concept, a user study was conducted.

The development of the game and its variants demonstrated that the APEX platform provides a valuable tool for the rapid development of serious games. The possibility of component reuse was particularly useful. The first versions of the game relied on components from prototypes that had been developed with the framework. This included both objects in the environment, and behavioural models. As ideas matured, these components were either refined, or replaces by new ones.

The study revealed that, although the virtual environment did capture the attention of children, there is a need to restrict what avatars can do in the environment to better focus the players on the goal of the game. With the lessons learnt, a second version of the game has been developed. Changes involved the configuration of the virtual world. The logic of the game remained mostly the same. A second edition of the study, with this new version of the game, is currently being prepared to assess the inpact of the reconfiguration of the envirenment. Changes to the game play (hence the game logic) are being considered, but decisions will wait for the results of the second users study. 


\section{Acknowledgements}

This work is funded by ERDF - European Regional Development Fund through the COMPETE Programme (operational programme for competitiveness) and by National Funds through the FCT - Fundação para a Ciência e a Tecnologia (Portuguese Foundation for Science and Technology) within project FCOMP-01-0124-FEDER-015095.

Tiago Gomes and Tiago Abade are funded by grants with references BI2-2013_PTDC/EIA-EIA/116069/2009_UMINHO and BI1-2013_PTDC/EIA-EIA/116069/2009_UMINHO, respectively.

The authors also thank the Taipas Group of Schools, and in particular Julia Correia and her students, for their collaboration in the user study.

\section{REFERENCES}

[1] C. C. Abt. Serious games. The Viking Press, 1970.

[2] L. J. Akinbami and K. C. Schoendorf. Trends in childhood asthma: Prevalence, health care utilization, and mortality. Pediatrics, 110(2):315-322, August 2002.

[3] T. Baranowski, R. Buday, D. I. Thompson, and J. Baranowski. Playing for real: Video games and stories for health-related behavior change. American Journal of Preventive Medicine, 34(1):74-82, 2008.

[4] M. N. K. Boulos, L. Hetherington, and S. Wheeler. Second Life: an overview of the potential of 3-D virtual worlds in medical and health education. Health Information \& Libraries Journal, 24(4):233-245, 2007.

[5] U. EPA. Asthma Home Environment Checklist, United States Environmental Protection Agency, 2004.

[6] K. Jensen and L. M. Kristensen. Coloured Petri Nets: Modelling and Validation of Concurrent Systems. Springer, 2009.

[7] J. A. Kientz, S. N. Patel, B. Jones, E. Price, E. D. Mynatt, and G. D. Abowd. The georgia tech aware home. In CHI '08 Extended Abstracts on Human Factors in Computing Systems, CHI EA '08, pages 3675-3680, New York, NY, USA, 2008. ACM.

[8] H. Mouaheb, A. Fahli, M. Moussetad, and S. Eljamali. The serious game: What educational benefits? Procedia - Social and Behavioral Sciences, 46:55025508, 2012.

[9] J. Silva, J. Campos, and M. Harrison. Formal analysis of ubiquitous computing environments through the apex framework. In ACM Symposium on Engineering Interactive Computing Systems (EICS2012), pages 131-140. ACM, 2012.

[10] J. L. Silva, O. R. Ribeiro, J. M. Fernandes, J. C. Campos, and M. D. Harrison. The apex framework: prototyping of ubiquitous environments based on petri nets. In Human-Centred Software Engineering, volume 6409 of Lecture Notes in Computer Science, pages 6-21. Springer, 2010

[11] D. Thompson, T. Baranowski, R. Buday, J. Baranowski, V. Thompson, R. Jago, and M. J. Griffith. Serious video games for health: How behavioral science guided the development of a serious video game. Simulation \& Gaming, 41(4):587-606, 2010.

[12] M. Zyda. From visual simulation to virtual reality to games. IEEE Computer, 38(9):25-32, September 2005.

\section{APPENDIX}

\section{A. QUESTIONNAIRE}

The questionnaire used in the users study to evaluate the Asthma Game is presented below (translated from the Portuguese original).

\begin{tabular}{|c|c|c|c|c|}
\hline \multicolumn{5}{|c|}{ Subject characterization } \\
\hline 1 & Age & & & \\
\hline \multirow[t]{3}{*}{2} & Gender & \multirow[b]{2}{*}{ No } & \multirow[b]{2}{*}{$\begin{array}{l}\text { So- } \\
\text { so }\end{array}$} & \multirow[b]{2}{*}{ Yes } \\
\hline & & & & \\
\hline & & : & 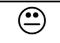 & (;) \\
\hline 3 & Do you often play computer games? & & & \\
\hline 4 & Have you ever played a game like this? & & & \\
\hline 5 & $\begin{array}{l}\text { Do you know OpenSimulator or Sec- } \\
\text { ondLife? }\end{array}$ & & & \\
\hline 6 & $\begin{array}{l}\text { Do you already know any respiratory } \\
\text { disease? }\end{array}$ & & & \\
\hline \multicolumn{5}{|c|}{ Utility } \\
\hline 7 & $\begin{array}{l}\text { The game helped you to better under- } \\
\text { stand what is asthma? }\end{array}$ & & & \\
\hline 8 & $\begin{array}{l}\text { Do you think you can now help more } \\
\text { people with respiratory diseases? }\end{array}$ & & & \\
\hline 9 & $\begin{array}{l}\text { Will you apply at home what you } \\
\text { have learned? }\end{array}$ & & & \\
\hline 10 & $\begin{array}{l}\text { Now you know what to do at home to } \\
\text { prevent respiratory probl? }\end{array}$ & & & \\
\hline \multicolumn{5}{|c|}{ Ease of use } \\
\hline 11 & Is it easy to play? & & & \\
\hline 12 & $\begin{array}{l}\text { Is it simple to walk through the } \\
\text { game's house? }\end{array}$ & & & \\
\hline 13 & $\begin{array}{l}\text { Is it possible to play without previous } \\
\text { instructions? }\end{array}$ & & & \\
\hline 14 & $\begin{array}{l}\text { Is it more easy to reply to those ques- } \\
\text { tions or to the game questions? }\end{array}$ & & & \\
\hline \multicolumn{5}{|c|}{ Learning } \\
\hline 15 & Were the questions difficult? & & & \\
\hline 16 & $\begin{array}{l}\text { Did you learn something about respi- } \\
\text { ratory diseases? }\end{array}$ & & & \\
\hline 17 & $\begin{array}{l}\text { If you have to make a test about respi- } \\
\text { ratory diseases, would it be more easy } \\
\text { now? }\end{array}$ & & & \\
\hline 18 & $\begin{array}{l}\text { Can you explain how to proceed in } \\
\text { order to prevent asthma attacks? }\end{array}$ & & & \\
\hline \multicolumn{5}{|c|}{ Satisfaction } \\
\hline 19 & $\begin{array}{l}\text { Are asthma triggers well represented } \\
\text { in the game? }\end{array}$ & & & \\
\hline 20 & $\begin{array}{l}\text { Was it funny to play the asthma } \\
\text { game? }\end{array}$ & & & \\
\hline 21 & $\begin{array}{l}\text { Is it tempting, to try to figure out all } \\
\text { the questions to complete the game? }\end{array}$ & & & \\
\hline 22 & $\begin{array}{l}\text { Have you easily identified the mo- } \\
\text { ments when the game started and } \\
\text { when it finished? }\end{array}$ & & & \\
\hline 23 & Would you recommend the game? & & & \\
\hline
\end{tabular}

